\title{
Laminated veneer lumber from spindleless rotary-peeled veneers produced from short rotation, small Hevea plantation logs: effects of lamination pressure
}

\begin{abstract}
The invention of spindleless lathe technology has enabled veneers to be produced from small $\operatorname{logs}$, such as logs from short rotation Hevea plantations, with low recovery loss. However, for structural laminated products, such as laminated veneer lumber (LVL), manufacturers are highly selective regarding the veneers for their conventional production. During the peeling process of small $\operatorname{logs}(<18 \mathrm{~cm})$, deeper and higher frequency of lathe checks were induced on veneer surface compared to the common $\log$ size used $(>30 \mathrm{~cm})$. In this study, spindleless rotary-peeled veneers made from small rubber logs were processed into LVL using different lamination pressures: 7, 8, 9, and $10 \mathrm{kgf} / \mathrm{cm} 2$. The effects of lamination pressures on the physical and mechanical properties of the produced LVL were evaluated. Based on the findings, the specific gravity increased from 0.73 to 0.83 with increased lamination pressure. In terms of mechanical properties, all the values increased with lamination pressure, but with a sudden drop with $10 \mathrm{kgf} / \mathrm{cm} 2$. Understanding the effect of lamination pressure on the physical and mechanical properties can shed light on optimizing the usage of spindleless rotary-peeled veneers from small logs for the production LVL and other lamination products.
\end{abstract}

Keyword: Laminated veneer lumber; Small Hevea log; Spindleless rotary-peeled veneers; Lamination pressure; Physical properties; Mechanical properties 